\title{
The partial reinforcement acquisition effect in preweanling and juvenile rats
}

\author{
JAW-SY CHEN, KEITH GROSS, MARK STANTON, and ABRAM AMSEL \\ University of Texas, Austin, Texas 78712
}

\begin{abstract}
Evidence of the partial reinforcement acquisition effect (PRAE), faster running after partial reinforcement than after continuous reinforcement in the start and run segments coupled with slower running in the goal segment of a straight-alley runway, was obtained in preweanling (18-20 days of age) and young adult (52-54 days of age) rats. While present at both ages, the PRAE appears to increase with age. The results are discussed in relation to previous studies of this and other paradoxical reinforcement effects.
\end{abstract}

Among the many paradoxical effects of reinforcement in discrete-trial instrumental learning is the partial reinforcement acquisition effect (PRAE). The PRAE, first shown by Goodrich (1959) and others (Haggard, 1959; Wagner, 1961), refers to the finding that, during acquisition, partially reinforced (PRF) subjects attain faster asymptotic running speeds than continuously reinforced (CRF) subjects in the start and run segments of a straight-alley runway but run slower than CRF subjects in the goal segment. Theoretical interpretations of this effect have attributed it to greater emotionality in the PRF subjects, brought on by the intermittent presentation of reward and nonreward. This is true of Amsel's (1967) account, which postulates (1) the simultaneous operation of approach and avoidance gradients in PRF subjects-the former reflecting incentive motivation and the latter brought about by frustrative nonreward-which, after Miller (1959), are of different slope, and (2) that conditioned frustration energizes the instrumental response at weak intensities (i.e., far from the goal) but competes with it at high intensities (i.e., near the goal). A similar, although more formal, account is represented by Gray and Smith's (1969) arousal-decision model of the PRAE. Consistent with interpretations of this effect in terms of emotionality are reports that the PRAE can be eliminated by the administration of tranquilizing drugs such as sodium amobarbital (Gray, 1969; Wagner, 1963).

The present experiment looked for the PRAE in preweanling rats. The performance of 18-day-old rat pups was compared with that of 52-day-olds (young adults) over the course of PRF acquisition. As such, it is part of a larger effort on our part directed at the ontogeny of the many paradoxical effects of reward (Amsel, 1979; Amsel \& Stanton, 1980). Existing evidence is somewhat conflicting as to what results to expect. Whereas evidence for the presence of conditioned frustration in preweanlings has been obtained in experiments on partial reinforcement extinction effect (PREE) (Chen \& Amsel, in press; Letz, Burdette, Gregg, Kittrell, \& Amsel, 1978), other phenomena that, in theory, depend on conditioned frustration, for example, successive negative contrast (SNC) and the magnitude of reward extinction effect (MREE), do not seem to be present until just after the time of weaning (Chen, Gross, \& Amsel, in press; Stanton \& Amsel, 1980). In general, we have found that paradoxical effects involving intermittent reward appear earlier in ontogeny than those involving phase changes in the magnitude or presence of continuous reward. This would lead us to expect the PRAE to be present in preweanling rats. On the other hand, it also seems generally true that robust effects first appear at younger ages than do weaker ones. Because the PRAE is not an extremely robust effect, we might expect it not to be present in preweanling rats.

Existing evidence on age differences in the PRAE is unclear (Amsel \& Chen, 1976; Burdette, Brake, Chen, \& Amsel, 1976; Chen \& Amsel, 1975), largely because procedures have varied among experiments. Using a large reward (one 300-mg food pellet), Chen and Amsel (1975) obtained a PRAE in 30- to 44-day-old rats, but they failed to test younger rats under the same conditions. Amsel and Chen (1976) and Burdette et al. (1976) tested several ages (range $=18-65$ days) under the same conditions, but the reward magnitude they used (two 45-mg pellets) apparently prevented the PRAE from appearing, even in the oldest animals tested. Thus, when the effect is absent in young animals, it can be attributed to training conditions that are not sufficient to produce the effect in older animals, and higher reward magnitude seems to be an important parameter.

The present report attempts to clear up this matter. Animals of two ages (18 and 52 days) were run together in a single experiment to an intermediate reward magnitude (one 190-mg pellet) under conditions most similar to Amsel and Chen (1976) and Burdette et al. (1976).

\section{METHOD}

\section{Subjects}

Subjects were 168 male and female albino rats of the SpragueDawley strain, bred and reared in our laboratory. Half of the 
subjects were 18 days old at the start of the experiment, and half were 52 days old (birth = Day 0$)$. Subjects were run in 14 squads of 12 subjects each.

\section{Apparatus}

A straight-alley runway was used. It consisted of a $27-\mathrm{cm}$ startbox, a $66.5-\mathrm{cm}$ run section, and a $32-\mathrm{cm}$ goalbox. The startbox opened at one end and narrowed from 7.3 to $5 \mathrm{~cm}$. The run section widened from $5 \mathrm{~cm}$ to $7.3 \mathrm{~cm}$. The goalbox was $7.3 \mathrm{~cm}$ wide. All sections were $7.5 \mathrm{~cm}$ high. The start door was opaque Plexiglas. The goalbox door was black sheet metal. The food cup was metal, $2.7 \mathrm{~mm}$ in diameter, $1 \mathrm{~cm}$ deep, and attached to the rear wall of the goalbox. Its lip was $1.5 \mathrm{~cm}$ from the floor. The floors were gray, and the walls were black. The entire runway was covered with clear Plexiglas. The start door was opened by pulling on a string; this operated a microswitch to start the first timer. Three photocells, spaced $30.5 \mathrm{~cm}$ apart, provided three time measures (start, run, and goal) for each trial.

\section{Procedure}

Subjects were deprived of food for $36 \mathrm{~h}$ prior to the start of training. The younger subjects were separated from the nest and placed on deprivation on the evening of Day 16, and the older subjects were placed on food deprivation on the evening of Day 50. Twenty-four hours later, each subject was placed in the goalbox four times. It received a $190-\mathrm{mg}$ Noyes pellet on each placement. No other food was received before training. On the following morning, the experiment proper began.

Subjects received 48 acquisition trials in seven sessions of $4,4,8,8,8,8$, and 8 trials, two sessions per day for 3.5 days. Daily sessions were run $12 \mathrm{~h}$ apart, one at $0800 \mathrm{~h}$ and one at $2000 \mathrm{~h}$. Each session began by transporting the 12 subjects in each squad from their home cages to holding compartments adjacent to the runway in which they resided between trials. These $10 \times 25 \times 10 \mathrm{~cm}$ holding compartments had wooden walls, a wire-mesh floor, and a sliding sheet metal roof/entrance and were continuously supplied with water. The 12 animals in each squad were run in rotation, each receiving a given trial before going to the next trial. This created an intertrial interval (ITI) of 12-20 min. The order of running animals was randomized from session to session. On each trial, the rat was taken from its holding compartment and placed in the startbox. When the subject oriented toward it, the startbox door was raised. Upon breaking the last (goal segment) photocell, the goalbox door was lowered, and the subject was allowed 30$60 \mathrm{sec}$ to consume the reward. If the subject took longer than $60 \mathrm{sec}$ in any runway segment, it was manually placed in the goalbox. Following consumption of the reward, the subject was returned to its holding compartment. Reward consisted of a single 190-mg Noyes food pellet. At the end of each session, subjects were returned to their home cages, and 15-30 min later they were given the remainder of half their daily ration. The daily ration included the food received during reward training and was 4,5 , and $6 \mathrm{~g}$ for the young animals on Days 18, 19, and 20, respectively; for the old animals, it was 4,6 , and $7 \mathrm{~g}$ on Days 52 , 53 , and 54 , respectively.

Half of the subjects of each squad were 52 days old and half were 18 days old at the start of training. Of the subjects in each age group, half were given CRF and half, PRF training. Gender was counterbalanced across age and groups. The PRF training schedule was RNNR, RRNN, NRNRRNRN, NRRNNNRR, NRNRRRNN, RNRNNRRN, and RNNRNNRR, respectively, for each of the seven acquisition sessions.

\section{RESULTS}

The results appear in Figure 1. Data were analyzed by means of an analysis of variance involving the between-

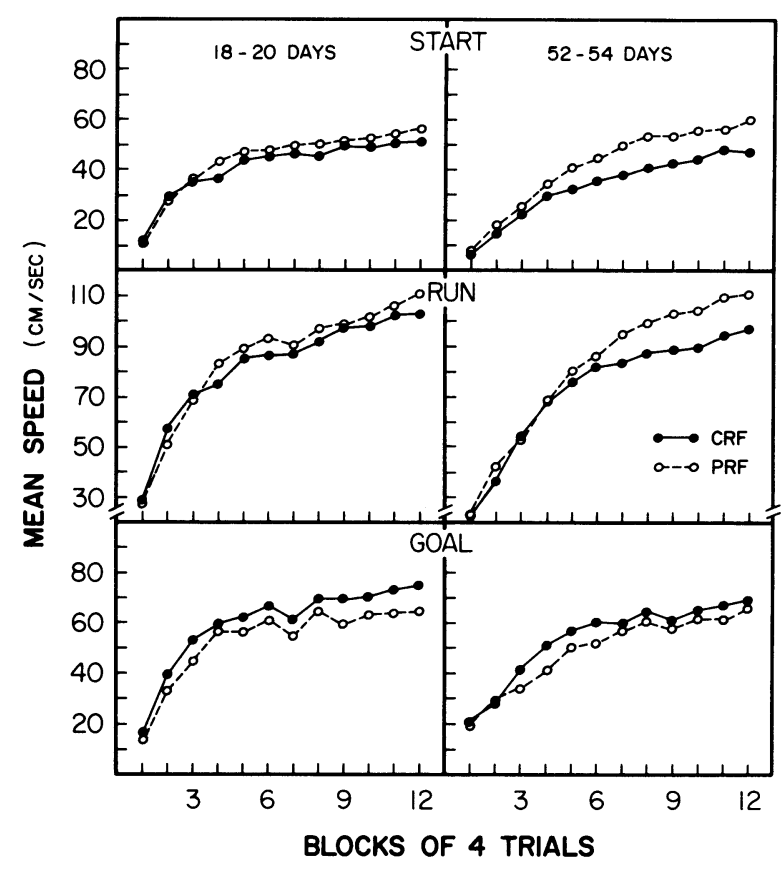

Figure 1. Acquisition of a runway response on a continuous (CRF) or a partial (PRF) reinforcement schedule in preweanling (aged 18-20 days) and young adult (aged 52-54 days) rats. At each age, running speeds are shown in the start, run, and goal segments of the runway.

groups factors of age and schedule and the withingroups factors of blocks and trials. Separate analyses were run on each alley segment.

\section{Start Segment}

All animals acquired the running response [blocks main effect, $F(11,1232)=467.06, p<.0001]$, and the young animals ran faster than the old animals [age $\mathrm{F}(1,112)=17.97, \mathrm{p}<.001]$, although this might reflect the 18-day-olds' faster rate of acquisition [Blocks by Age $F(11,1232)=13.42, p<.0001]$, rather than age differences in asymptote. More important, the PRF animals ran faster than the CRF animals [schedule main effect, $F(1,112)=19.78, p<.001]$, and this effect emerged with training [Schedule by Blocks $F(11,1232)=5.79, p<.001]$. Of most interest were the significant interactions of Age by Schedule $[F(1,112)=$ $4.49, \mathrm{p}=.036]$ and Age by Schedule by Blocks $[F(11,1232)=1.78, p=.052]$, which suggested that with training, the groups effect became larger in the older animals than in the younger animals. This impression was confirmed in post hoc tests (all such tests are Newman-Keuls) that showed that the Age by Schedule interaction resulted from a significant schedule effect ( $\mathrm{p}$ $<.01$ ) at 52-54 but not at 18-20 days of age. Tests of the Age by Schedule by Blocks interaction showed that, whereas no significant age or schedule effects were present in the first block, a schedule effect was present at both ages in the last block, although it was more reliable in the older $(\mathrm{p}<.01)$ than in the younger $(\mathrm{p}<.05)$ subjects. 


\section{Run Segment}

The results of the run measure ANOVA were similar to those obtained in the start segment. Acquisition of the running response occurred [blocks $F(11,1232)=$ $799.47, \mathrm{p}<.0001]$, although it was more rapid in the younger animals [age $F(1,112)=5.93, p=.016$; Age by Blocks $F(11,1232)=9.15, p<.001]$. Again, the PRF animals ran faster than the CRF animals [schedule $F(1,112)=4.89, p=.029$ ] ; this effect emerged with training [Blocks by Schedule $F(11,1232)=6.20$, $\mathrm{p}<.001$ ] and was greater in the older animals than in the younger animals [Age by Schedule by Blocks $\mathrm{F}(11,1232)=3.47, \mathrm{p}<.001]$ (the Age by Schedule interaction was not significant). Post hoc tests of this third-order interaction showed no effect of schedule or age on Block $1(\mathrm{p}>.05)$ and a significant $(\mathrm{p}<.01)$ schedule effect in the older but not the younger animals on Block 12.

\section{Goal Segment}

Analysis of the goal measure also revealed a main effect of blocks $[F(11,1232)=411.28, p<.0001]$, age $[F(1,112)=7.46, p=.007]$, and an interaction of Blocks by Age $[F(11,1232)=9.49, p<.001]$, indicating again that the younger animals acquired the running response faster than the older animals. In the goal segment, unlike the start and run segments, the PRF animals ran more slowly than the CRF animals [schedule $F(1,112)=10.24, p=.002]$. This effect did not interact with blocks or age, although the Age by Schedule by Blocks interaction was significant $[F(11,1232)=2.52$, $\mathrm{p}=.004]$. Inspection of Figure 1 leads to the impression that this interaction reflected a larger schedule effect in the younger animals that emerged across blocks. NewmanKeuls tests showed no age or schedule effects on Block 1 $(p>.05)$, coupled with a significant $(p<.01)$ schedule effect in the young but not the old animals on Block 12 .

In summary, all of these analyses confirm the presence of an overall (i.e., collapsed across ages) PRAE: PRF subjects run faster than CRF subjects in the start and run measures and slower in the goal measure. The various interactions involving age suggest that the faster running of the PRF subjects in the early runway segments is more marked at 52 days, whereas the slower running of these subjects in the goal segment is more marked at 18 days of age.

\section{DISCUSSION}

The present report establishes for the first time an unequivocal PRAE in preweanling rats. With regard to the previously published reports, it supports the conclusion that preweanlings will show the PRAE if they are run under conditions that produce the PRAE in older animals. Such a principle explains the previous failures to obtain this effect clearly in young animals (Amsel \& Chen, 1976; Burdette et al., 1976; Chen \& Amsel, 1975). The present report, in conjunction with these earlier ones, also argues that the factor that is critical in obtain- ing this effect, at any age, is reward magnitude. Chen and Amsel (1975) obtained the PRAE in juvenile rats with a very large reward (300 $\mathrm{mg}$ ) and distributed trials, whereas Amsel and Chen (1976) and Burdette et al. (1976) failed to obtain the effect at any age with a smaller reward (two $45-\mathrm{mg}$ pellets) and more massed trials. The present investigation entailed a distribution of trials most similar to the latter two reports but used a larger reward (one 190-mg pellet); hence, differences in reward magnitude are sufficient to explain these apparently contradictory results.

The present report also shows that the PRAE becomes larger with age. However, as in all ontogenetic comparisons, these apparent age differences might be attributable to a failure to make the conditions encountered by the young and old animals comparable. For instance, it could be argued that the smaller size and weight of the preweanling rats makes a $190-\mathrm{mg}$ pellet a larger reward or a $91.5-\mathrm{cm}$ runway a longer runway, relative to the older subjects. Neither of these arguments, however, can explain the pattern of results found in the present report, because both of these variables serve to enhance rather than attenuate the PRAE. Viewed in this way, we have, if anything, underestimated any age differences that may exist.

Finally, the presence of the PRAE in preweanling rats provides further evidence of frustrative emotionality in infant rats and is consistent with the presence of the PREE at this age and younger (Amsel, 1979). In addition, it further corroborates the empirical generalization that paradoxical reward effects that arise from intermittent reward are present at earlier ages than those that arise from continuous reward.

\section{REFERENCES}

Amsel, A. Partial reinforcement effects on vigor and persistence: Advances in frustration theory derived from a variety of withinsubjects experiments. In K. W. Spence \& J. T. Spence (Eds.), The psychology of learning and motivation (Vol. 1). New York: Academic Press, 1967.

AmSEL, A. The ontogeny of appetitive learning and persistence in the rat. In N. E. Spear \& B. A. Campbell (Eds.), Ontogeny of learning and memory. Hillsdale, N.J: Erlbaum, 1979.

Amsel, A., \& Chen, J. Ontogeny of persistence: Immediate and long-term persistence in rats varying in training age between 17 and 65 days. Journal of Comparative and Physiological Psychology, 1976, 90, 808-820.

Amsel, A., \& Stanton, M. The ontogeny and phylogeny of the paradoxical reward effects. In J. S. Rosenblatt, R. A. Hinde, C. Beer, \& M. Busnel (Eds.), Advances in the study of behavior. New York: Academic Press, 1980.

Burdette, D. R., Brake, S., Chen, J., \& Amsel, A. Ontogeny of persistence: Immediate extinction effects in preweanling and weanling rats. Animal Learning \& Behavior, 1976, 4, 131-138.

Chen, J., \& Amsel, A. Durability and retention of persistence acquired by young and infant rats. Journal of Comparative and Physiological Psychology, 1975, 89, 238-245.

Chen, J., \& Amsel, A. Learned persistence at 11-12 but not at 10-11 days in infant rats. Developmental Psychobiology, in press.

Chen, J., Gross, K., \& Amsel, A. Ontogeny of successive negative contrast and its dissociation from other paradoxical reward effects in preweanling rats. Journal of Comparative and Physiological Psychology, in press.

Goodrich, K. P. Performance in different segments of an instrumental response chain as a function of reinforcement schedule. Journal of Experimental Psychology, 1959, 57, 57-63.

Gray, J. A. Sodium amobarbital and effects of frustrative nonreward. Journal of Comparative and Physiological Psychology, $1969,69,55-64$.

Gray, J. A., \& Smith, P. T. An arousal-decision model for partial reinforcement and discrimination learning. In R. Gilbert 
\& N. S. Sutherland (Eds.), Animal discrimination learning. New York: Academic Press, 1969.

HAGGARD, D. F. Acquisition of a simple running response as a function of partial and continuous schedules of reinforcement. Psychological Record, 1959, 9, 11-18.

Letz, R., Burdette, D. R., GregG, B., Kittrell, E. M. W., \& Amsel, A. Evidence for a transitional period for the development of persistence in infant rats. Journal of Comparative and Physiological Psychology, 1978, 92, 856-866.

Miller, N. E. Liberalization of basic S-R concepts: Extensions to conflict behavior, motivation and social learning. In S. Koch (Ed.), Psychology: A study of a science (Study 1, Vol. 2). New York: McGraw-Hill, 1959.
Stanton, M., \& Amsel, A. Adjustment to reward reduction (but no negative contrast) in rats 11,14 , and 16 days of age. Journal of Comparative and Physiological Psychology, 1980, 94, 446-458.

WAGNER, A. R. Effects of amount and percentage of reinforcement and number of acquisition trials on conditioning and extinction. Journal of Experimental Psychology, 1961, 62, 234-242.

WAGNeR, A. R. Sodium amytal and partially reinforced runway performance. Journal of Experimental Psychology, 1963, 65, 474-477.

(Received for publication August 4, 1980.) 